Jurnal Ilmu Ilmu Agribisnis: Journal of Agribusiness Science, 9(3), Agustus 2021

\title{
SIKAP, KEPUASAN, DAN LOYALITAS KONSUMEN TERHADAP PRODUK SARI APEL UMKM APELNESIA, KOTA BATU DENGAN PENDEKATAN BAURAN PEMASARAN 4P
}

\author{
(Attittude, Satisfaction, and Loyalty of Consumers Towards Apelnesia MSME Apple Extract Product, Batu \\ City with Marketing Mix 4P Approach)
}

Muhammad Rifky Setiadi, Febriananda Faizal, Destyana Ellingga Pratiwi

Jurusan Sosial Ekonomi, Fakultas Pertanian, Universitas Brawijaya, Jl. Veteran, Fakultas Pertanian

Universitas Brawijaya, Malang 65145, Indonesia, Telp.0341 551611,E-mail: rfkysetiadi@gmail.com

\begin{abstract}
Massive apple production drives MSMEs in Batu City to process the fruit, as an example, apple extract. With so many MSMEs that make apple extract, creates higher market competitiveness. One of the MSMEs that makes apple extract is Apelnesia. The purpose of this research is to study attitude, satisfaction, and loyalty of consumers towards Apelnesia MSME apple extract product. The basic method of this research is a quantitative analysis. The sampling method uses non-probability method with time linear function technique. This research uses Fishbein analysis, Importance Performance Analysis, Customer Satisfaction Index, and Loyalty Pyramid. The results showed that consumer attitude is Quiet Positive. Importance Performance Analysis showed the attributes that needs improvement i.e. Packaging (X1.4), Price equals quality (X2.1), Easy product access (X3.1), and Strategic location (X3.3). Satisfaction level of consumers according to Customer Satisfaction Index is Satisfied. Loyalty Pyramid showed that the highest level of consumer loyalty is Liking the brand with 71.88 percent.
\end{abstract}

Key words: apple extract, attitude, loyalty, marketing mix, satisfaction

\section{PENDAHULUAN}

Kota Batu merupakan salah satu kota yang menghasilkan buah apel dengan jumlah yang besar di Indonesia. Kota Batu juga dijuluki sebagai kota apel dan menjadikan buah apel sebagai ikonnya. BPS (2019) mencatat bahwa pada tahun 2018 buah apel merupakan buah yang jumlah produksinya paling besar dibandingkan buah lainnya, yaitu sebesar 54.126 ton.

Produksi buah apel yang besar mendorong Usaha Mikro Kecil Menengah (UMKM) di Kota Batu untuk mengolahnya menjadi sebuah produk yang memiliki nilai jual berbeda, contohnya adalah sari apel. Banyaknya UMKM yang bergerak di bidang pengolahan buah apel menjadi sari apel menciptakan tingkat persaingan yang tinggi. Persaingan yang tinggi antar UMKM dapat menciptakan risiko usaha bagi para pelaku usaha dalam menjalankan usahanya. Oleh karena itu, diperlukan usaha atau strategi bisnis untuk dapat mempertahankan bisnisnya diantara pesaingpesaing yang ada.

Apelnesia merupakan UMKM yang memproduksi sari apel dan tergolong ke dalam usaha mikro dengan omzet sebesar Rp240.000.000 per tahun. Hal ini sesuai dengan Undang-Undang Republik
Indonesia Nomor 20 Tahun 2008, dimana usaha mikro merupakan usaha yang memiliki omzet maksimum sebesar Rp300.000.000 per tahun. Usaha sari apel Apelnesia sudah berjalan selama 2 tahun. Namun, jika dilihat dari pesaing-pesaingnya seperti Brosem dan Siiplah yang sudah berdiri lebih dari 5 tahun, maka Apelnesia perlu mengembangkan produknya agar mampu bersaing dengan usaha lainnya.

Tingkat persaingan yang tinggi menuntut pelaku usaha untuk memikirkan perilaku konsumen, agar dapat mengetahui kebutuhan konsumen pada saat ini maupun masa yang akan datang. Salah satu yang mempengaruhi perilaku konsumen adalah sikap konsumen. Menurut Suryani (2008), sikap konsumen adalah faktor psikologis yang perlu dipahami oleh pemasar, karena sikap dianggap mempunyai korelasi yang positif dan kuat dengan perilaku konsumen. Dengan memahami sikap konsumen, maka pemahaman perilaku konsumen akan semakin baik, sehingga strategi pemasaran yang diterapkan menjadi lebih efektif.

Produk sari apel UMKM Apelnesia harus memiliki nilai-nilai yang dapat menumbuhkan kepuasan konsumennya. Kepuasan akan tumbuh jika produk memenuhi kebutuhan dan sesuai dengan harapan dari konsumen. Menurut Saladin (2003), kepuasan 
konsumen adalah rasa senang atau kecewa konsumen yang berasal dari perbandingan antara kesannya terhadap hasil suatu produk dengan harapan-harapan dari konsumen tersebut. Konsumen yang merasa puas akan produk yang dihasilkan suatu pelaku usaha maka nantinya konsumen akan melakukan pembelian kembali (repeat order).

Loyalitas konsumen merupakan sesuatu yang perlu diperoleh oleh sebuah pelaku usaha, karena dengan loyalitas konsumen diharapkan pelaku usaha akan mendapatkan keuntungan jangka panjang atas hubungan mutualisme yang terjalin dalam kurun waktu tertentu. Loyalitas konsumen muncul disebabkan oleh rasa senang dan puas konsumen terhadap produk maupun layanan yang diberikan oleh sebuah perusahaan. Menurut Hasan (2008), loyalitas konsumen adalah konsumen yang merasa puas akan produk atau jasa perusahaan, sehingga ia membeli produk secara teratur dan berulang-ulang. Loyalitas juga menumbuhkan rasa antusiasme dari konsumen untuk memperkenalkan produk tersebut kepada siapapun yang ia kenal.

Maka dari itu, penulis tertarik untuk melakukan penelitian terhadap sikap, kepuasan, dan loyalitas konsumen pada produk sari apel UMKM Apelnesia. Tujuan dari penelitian ini adalah untuk mengkaji sikap, tingkat kepuasan, dan tingkat loyalitas konsumen dari produk sari apel UMKM Apelnesia.

\section{METODE PENELITIAN}

Objek penelitian ini adalah UMKM Apelnesia yang bertempat di Kota Batu pada bulan Februari tahun 2020 selama kurun waktu 30 hari. Penentuan lokasi penelitian dilakukan secara purposive dengan pertimbangan bahwa Apelnesia merupakan UMKM yang tergolong ke dalam usaha mikro maka dari itu Apelnesia perlu mengembangkan usahanya ke tingkat yang lebih tinggi, agar dapat memiliki pasar yang kuat dan bersaing dengan usaha lainnya. Penentuan jumlah sampel ditentukan dengan metode accidental sampling. Jumlah responden pada penelitian ini yaitu 32 responden yang diperoleh melalui rumus time linear function.

Penelitian ini dijalankan menggunakan metode survey. Data dikumpulkan menggunakan kuisioner sebagai alat wawancara. Kuisioner penelitian memiliki empat bagan pertanyaan yaitu identitas responden, tingkat kinerja, loyalitas, dan tingkat kepentingan. Identitas responden terdiri dari nama, domisili, usia, jenis kelamin, dan pendapatan per bulan. Tingkat kinerja dan kepentingan dijadikan penilaian terhadap sikap serta kepuasan konsumen. Loyalitas terdiri dari pernyataan yang merujuk pada switcher buyer, habitual buyer, satisfied buyer, liking the brand, dan committed buyer. Pengumpulan data dilakukan pada bulan Februari sampai Maret tahun 2020.

Uji validitas dan reliabilitas perlu dilakukan sebelum melanjutkan analisis data. Uji validitas menggunakan Statistical Package for the Social Sciences (SPSS 24) dengan jumlah responden sebesar 15 responden. Uji validitas menggunakan tingkat signifikasi sebesar 5 persen dengan $r$ tabel 0,514 . Seluruh item pertanyaan dinyatakan valid, dikarenakan $r$ hitung lebih besar dari $r$ tabel. Uji reliabilitas menggunakan rumus Cronbach Alpha dengan menggunakan skala 0 sampai 1 . Seluruh item pertanyaan dinyatakan reliabel, karena nilainya di atas 0,60 dengan nilai Cronbach Alpha sebesar 0,904 pada kinerja, 0,828 pada loyalitas, dan 0,906 pada kepentingan.

Sikap konsumen dianalisis menggunakan Analisis Model Sikap Fishbein yang mencakup komponen evaluasi kepentingan (ei) dan komponen kepercayaan (bi) yang hasilnya berupa Ao (Attitude toward the object), yaitu sikap seseorang terhadap sebuah obyek yang dikenali lewat atributatribut yang melekat pada obyek tersebut (Adrianto 2018). Model sikap Fishbein digambarkan dengan rumus:

$$
\mathrm{A}_{0}=\sum_{\mathrm{i}=1}^{\mathrm{N}} \mathrm{b}_{\mathrm{i}} \cdot \mathrm{e}_{\mathrm{i}}
$$

Keterangan:

$A_{0}$ : Keseluruhan sikap terhadap suatu obyek

$b_{i}$ : Keyakinan konsumen terhadap atribut

$e_{i}$ : Evaluasi konsumen terhadap atribut

$N$ : Jumlah atribut yang dimiliki obyek

Importance Performance Analysis (IPA) digunakan untuk mengukur kepuasan pelanggan dengan melakukan analisa perbandingan kenyataan yang dirasakan oleh pelanggan dibandingkan dengan harapan pelanggan (Lusianti 2017). Kepuasan konsumen dipengaruhi oleh persepsi konsumen terhadap kinerja dari sebuah produk dalam memenuhi ekspektasi konsumen terhadap produk. 
Konsumen akan merasa puas jika kinerja dari produk memenuhi ekspektasi dan akan menjadi sangat puas jika kinerja melampau ekspektasi. Tahapan-tahapan IPA meliputi:

a. Tingkat kesesuaian

Tahapan pertama pada metode IPA adalah menentukan tingkat kesesuaian antara tingkat kepentingan dan tingkat kinerja kualitas atributatribut yang diteliti melalui perbandingan skor kinerja dengan skor kepentingan lalu dikalikan seratus persen.

b. Skor rata-rata

Menghitung skor rata-rata menggunakan jumlah skor rata-rata penilaian kinerja dan kepentingan lalu dibagi dengan jumlah responden.

c. Skor rata-rata total

Menghitung skor rata-rata seluruh atribut kinerja dan kepentingan lalu dibagi dengan jumlah atribut.

d. Diagram Kartesius

Hasil skor rata-rata dan skor rata-rata total akan menjadi titik dalam Diagram Kartesius yang dapat dilihat pada Gambar 1. Kuadran-kuadran yang ada terdiri dari A1 (keep up the good work), A2 (warning), B (concentrate here), C1 (low priority), $\mathrm{C} 2$ (improve), dan $\mathrm{D}$ (possible overkill).

Customer Satisfaction Index (CSI) digunakan untuk mengetahui tingkat kepuasan pengguna jasa atau produk secara menyeluruh dengan melihat tingkat kinerja dan tingkat kepentingan atau harapan dari atribut-atribut jasa atau produk tersebut (Devani dan Rizko 2016). Menurut Fitriana, Florencia, Dwi, Utomo, dan Tanto (2014), perhitungan Customer Satisfaction Index dapat dilakukan dalam empat langkah yaitu:

a. Mean Importance Score (MIS) dan Mean Satisfaction Score (MSS)

MIS dan MSS diperoleh dari rata-rata tingkat kepentingan dan kinerja yang dibagi dengan jumlah responden.

b. Weight Factor (WF)

WF diperoleh dengan mengubah nilai rata-rata kepentingan menjadi angka persentase dari total rata-rata tingkat kepentingan seluruh atribut, lalu dikalikan dengan seratus persen.

c. Weighting Score (WS)

WS diperoleh dari hasil perkalian WF dan MSS masing-masing atribut.

d. Menentukan CSI

Nilai kepuasan konsumen diperoleh dari jumlah total WS yang dibagi lima lalu dikalikan seratus persen, rentang nilai dapat dilihat pada Tabel 1 .

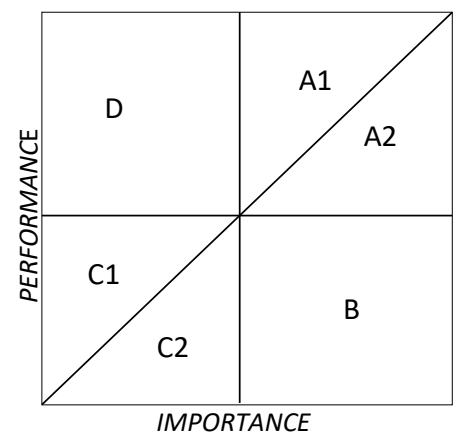

Gambar 1. Diagram Kartesius

Tabel 1. Rentang Skala CSI

\begin{tabular}{ccl}
\hline No & Skala $(\%)$ & Keterangan \\
\hline 1 & $81-100$ & Sangat Puas \\
2 & $66-80,99$ & Puas \\
3 & $51-65,99$ & Cukup Puas \\
4 & $35-50,99$ & Kurang Puas \\
5 & $0-34,99$ & Tidak Puas \\
\hline \multicolumn{2}{l}{ Sumber: Santoso (2011) }
\end{tabular}

Loyalitas konsumen diukur dengan menggunakan kategori persentase dari tingkatan Piramida Loyalitas yaitu Switcher buyer, Habitual buyer, Satisfied buyer, Liking of the brand, dan Committed buyer yang didasari oleh responden produk sari apel UMKM Apelnesia. Setiap responden diajukan pertanyaan yang merujuk kepada tingkatan piramida loyalitas. Persentase dilihat dari responden yang menjawab pernyataan dengan skala likert 4 dan 5. Bentuk piramida terbalik menandakan bahwa brand loyalty dari suatu produk itu kuat (Durianto, Sugiarto, dan Sitinjak 2004). Perhitungan persentasenya dapat dilihat pada Tabel 2.

\section{HASIL DAN PEMBAHASAN}

Konsumen produk sari apel UMKM Apelnesia yang menjadi responden sebagian besar memiliki jenis kelamin laki-laki dengan persentase 62,5 persen. Umur responden sebagian besar 17-25 tahun

\begin{tabular}{|c|c|c|}
\hline Tingkatan Loyalitas & & \\
\hline Skala likert $(\mathrm{X})$ & Frekuensi $(\mathrm{F})$ & F.X $\%$ \\
\hline 1 & & \\
\hline 2 & & \\
\hline 3 & & \\
\hline 4 & & \\
\hline 5 & & \\
\hline Total & & \\
\hline Rata-rata & & \\
\hline Tingkatan Loyalitas (\%) & & \\
\hline
\end{tabular}

Tabel 2. Perhitungan Tingkatan Loyalitas

Sumber: Widyasari, Prasmatiwi, dan Situmorang (2014) 
dengan persentase 62,50 persen dan sebagian besar berdomisili di Kota Malang dengan persentase 56,30 persen. Pendapatan per bulan responden sebagian besar di angka nominal Rp2.000.000 - Rp3.500.000 dengan persentase 31,30 persen.

\section{Analisis Model Sikap Fishbein}

Sikap konsumen merupakan perilaku yang menunjukkan apa yang disukai dan tidak disukai konsumen terhadap suatu obyek atau produk. Sikap tersebut dinilai menggunakan evaluasi konsumen (ei) dan tingkat kepercayaan (bi) terhadap produk sari apel UMKM Apelnesia. Nilai ei dan bi dapat dilihat pada Tabel 3.

Hasil nilai evaluasi (ei) terbesar berada pada atribut Rasa dengan nilai evaluasi (ei) sebesar 4,16. Atribut yang memiliki nilai evaluasi (ei) terkecil berada pada atribut Kemasan yaitu dengan nilai sebesar 3,06. Atribut yang memiliki nilai kepercayaan (bi) terbesar berada di atribut rasa dengan nilai kepercayaan (bi) sebesar 4,31. Atribut yang memiliki nilai kepercayaan (bi) terkecil berada pada atribut iklan dengan nilai sebesar 2,75. Hal ini sesuai dengan pernyataan Pratiwi, Deoranto, dan Putri (2014) yaitu salah satu atribut produk yang dianggap paling penting oleh konsumen ialah atribut rasa. Nilai rata-rata evaluasi (ei) secara keseluruhan yaitu sebesar 3,49 dan untuk nilai kepercayaan (bi) sebesar 3,80. Hal ini menunjukkan kinerja dari seluruh atribut produk sari apel UMKM Apelnesia yaitu baik dan kepercayaananya terhadap seluruh atribut adalah penting.

Nilai Attittude toward Object (Ao) terbesar berdasarkan Tabel 4 berada di atribut rasa yaitu sebesar 17,92. Atribut yang memiliki nilai Ao terkecil yaitu atribut pengelolaan media promosi sebesar 9,04. Produk sari apel UMKM Apelnesia merupakan produk konsumsi. Oleh karena itu, rasa produk merupakan hal yang sangat penting dan salah satu faktor penting yang dapat membuat konsumen merasa puas. Hasil penelitian ini sesuai dengan penelitian yang dilakukan oleh Pratama Indriani, dan Endaryanto (2017), yang menyatakan bahwa rasa produk merupakan atribut yang memiliki nilai Ao (Attitude toward Object) tertinggi. Rasa apel yang segar dan manis yang tidak mengganggu di tenggorokan merupakan ciri khas dari produk sari apel UMKM Apelnesia, dikarenakan proses pembuatan sari apel menggunakan mesin yang berkualitas dan rasa manis yang dihasilkan berasal dari gula alami.

Tabel 3. Nilai evaluasi (ei) dan kepercayaan (bi)

\begin{tabular}{|c|c|c|}
\hline Atribut & ei & $\mathrm{Bi}$ \\
\hline Kualitas & 3,81 & 4,13 \\
\hline Desain & 3,91 & 3,56 \\
\hline Rasa & 4,16 & 4,31 \\
\hline Kemasan & 3,06 & 4,25 \\
\hline Labelitas & 3,84 & 3,94 \\
\hline Harga sesuai kualitas & 3,09 & 4,16 \\
\hline Produk mudah diperoleh & 3,09 & 4,16 \\
\hline Stok & 3,63 & 3,63 \\
\hline Lokasi strategis & 3,13 & 4,19 \\
\hline Pengelolaan media promosi & 3,25 & 2,78 \\
\hline Iklan & 3,44 & 2,75 \\
\hline Rata-rata & 3,49 & 3,80 \\
\hline Total & 38,41 & 41,84 \\
\hline
\end{tabular}

Media promosi merupakan atribut yang penting dalam suatu produk, dikarenakan dapat mengetahui informasi terbaru pada produk dan promosipromosi yang diadakan. Pernyataan ini sesuai dengan penelitian yang telah dilakukan oleh Balakrishnan Balakrishnan, Bamini, Mohd dan Wong (2014) yang menunjukkan hasil bahwa electronic word of mouth, komunitas online, dan iklan online di media sosial berpengaruh terhadap persepsi konsumen terhadap produk yang nantinya berujung pada minat beli. Media promosi yang dipergunakan oleh UMKM Apelnesia adalah Instagram yang berisi iklan-iklan dari produk sari apelnya, namun aktivitas di akun tersebut sangat minim sehingga konsumen kurang mendapatkan informasi ataupun promo terbaru terkait produk.

Nilai Attittude toward Object (Ao) per atribut lalu dijumlahkan untuk melihat nilai Ao secara keseluruhan. Pada Tabel 4 dapat dilihat bahwa nilai Ao keseluruhan yaitu sebesar 146,15.

Tabel 4. Nilai Attitude toward Object (Ao)

\begin{tabular}{lc}
\hline \multicolumn{1}{c}{ Atribut } & ei x bi (Ao) \\
\hline Kualitas & 15,73 \\
Desain & 13,92 \\
Rasa & 17,92 \\
Kemasan & 13,02 \\
Labelitas & 15,13 \\
Harga sesuai kualitas & 12,86 \\
Produk mudah diperoleh & 12,86 \\
Stok & 13,14 \\
Lokasi strategis & 13,09 \\
Pengelolaan media promosi & 9,04 \\
Iklan & 9,45 \\
\hline \multicolumn{2}{c}{ Ao keseluruhan } \\
\hline
\end{tabular}


Tabel 5. Rentang skala Ao

\begin{tabular}{cl}
\hline Skala & \multicolumn{1}{c}{ Keterangan } \\
\hline $11-62,80$ & Sangat negatif \\
$63,80-115,60$ & Negatif \\
$116,60-168,40$ & Cukup positif \\
$169,40-221,20$ & Positif \\
$222,20-275$ & Sangat positif \\
\hline
\end{tabular}

Berdasarkan pada Tabel 5, sikap konsumen terhadap produk sari apel UMKM Apelnesia yaitu Cukup Positif.

\section{Importance Performance Analysis (IPA)}

Kepuasan konsumen pertama-tama dianalisis menggunakan Importance Performance Analysis (IPA) dikarenakan menurut Anggraeni, Deoranto, dan Ikasari (2015) metode IPA dapat menunjukkan atribut produk maupun jasa yang perlu ditingkatkan atau dikurangi, agar menjaga kepuasan konsumen. Tahap awal dari IPA yaitu mencari Tingkat kesesuaian (Tk) yang didapatkan dari perbandingan antara skor tingkat kepentingan dengan skor kinerja.

Berdasarkan Tabel 6, atribut yang memiliki nilai tingkat kesesuaian tertinggi yaitu atribut iklan menarik dengan nilai sebesar 125,00 persen. Atribut dengan tingkat kesesuaian terendah berada di atribut Kemasan produk dengan nilai sebesar 72,06 persen. Rata-rata keseluruhan tingkat kesesuaian atribut yaitu 93,95 persen. Menurut Sukardi dan Cholidis (2006), jika nilai dari tingkat kesesuaian mendekati 100 persen dan berada di atasnya, maka tingkat kesesuaian atribut dikatakan sudah baik.

Nilai rata-rata kinerja dan kepentingan pada Tabel 7 akan diubah menjadi Diagram Kartesius,

Tabel 6. Analisis tingkat kesesuaian

\begin{tabular}{lc}
\hline \multicolumn{1}{c}{ Atribut } & $\begin{array}{r}\text { Tingkat Kesesuaian } \\
(\%)\end{array}$ \\
\hline Kualitas & 92,42 \\
Desain & 109,65 \\
Rasa & 96,38 \\
Kemasan & 72,06 \\
Labelitas & 97,62 \\
Harga sesuai kualitas & 74,44 \\
Produk mudah diperoleh & 74,44 \\
Stok & 100,00 \\
Lokasi strategis & 74,63 \\
Pengelolaan media promosi & 116,85 \\
Iklan & 125,00 \\
\hline \multicolumn{2}{c}{$\quad$ Rata-rata } \\
\hline
\end{tabular}

dengan nilai kinerja sebagai sumbu $X$ dan nilai kepentingan sebagai sumbu Y. Nilai Rata-rata total akan menjadi titik pembatas, dimana nilai rata-rata total tingkat kinerja sebesar 3,46 di sumbu X dan nilai rata-rata total tingkat kepentingan sebesar 3,80 di sumbu Y. Nilai rata-rata atribut dan total pada tingkat kinerja serta kepentingan akan menentukan titik dimana atribut tersebut akan berada di kuadran dalam Diagram Kartesius. Atribut-atribut tersebut akan dijelaskan sesuai dengan kuadrannya.

Kuadran yang pertama adalah Kuadran A1, yaitu Keep up the good work. Atribut yang berada di kuadran ini memiliki kepentingan dan kinerja yang tinggi dan dapat memberikan peluang pada produk sari apel UMKM Apelnesia untuk bersaing. Ketiga atribut yang berada pada kuadran ini adalah kualitas produk (X1.1), rasa produk (X1.3), dan labelitas (X1.5).

Kuadran yang kedua adalah Kuadran B, yaitu Concentrate Here. Atribut yang berada di kuadran ini menunjukkan tingkat kepentingan yang tinggi, dengan tingkat kinerja yang rendah dan merupakan kelemahan utama produk sari apel UMKM Apelnesia, sehingga membutuhkan peningkatan secepat mungkin. Keempat atribut yang berada pada kuadran ini adalah kemasan produk (X1.4), harga sesuai kualitas produk (X2.1), kemudahan memperoleh produk (X3.1), dan lokasi Strategis (X3.3). Kuadran yang ketiga adalah Kuadran C1, yaitu Low Priority. Atribut yang berada di kuadran ini memiliki tingkat kepentingan yang rendah dengan tingkat kinerjanya yang tinggi, maka dari itu atribut tidak diprioritaskan pengembangannya. Kedua atribut tersebut adalah pengelolaan media promosi (X4.1) dan iklan menarik (X4.2).

Tabel 7. Rata-rata nilai kinerja dan kepentingan

\begin{tabular}{lcc}
\hline \multicolumn{1}{c}{ Atribut } & $\begin{array}{c}\text { Kepentingan } \\
(\mathrm{x})\end{array}$ & $\begin{array}{c}\text { Kinerja } \\
(\mathrm{y})\end{array}$ \\
\hline Kualitas & 4,13 & 3,81 \\
Desain & 3,56 & 3,91 \\
Rasa & 4,31 & 4,16 \\
Kemasan & 4,25 & 3,06 \\
Labelitas & 3,94 & 3,84 \\
Harga sesuai kualitas & 4,16 & 3,09 \\
Produk mudah diperoleh & 4,16 & 3,09 \\
Stok & 3,63 & 3,63 \\
Lokasi strategis & 4,19 & 3,13 \\
Pengelolaan media promosi & 2,78 & 3,25 \\
Iklan & 2,75 & 3,44 \\
\hline \multicolumn{2}{c}{ Rata-rata } & 3,80 \\
\hline
\end{tabular}


Tabel 8. Perhitungan Customer Satisfaction Index

\begin{tabular}{lrrrl}
\hline \multicolumn{1}{c}{ Atribut } & MIS & WF (\%) & MSS & WS \\
\hline Kualitas & 4,13 & 9,86 & 3,81 & 37,58 \\
Desain & 3,56 & 8,51 & 3,91 & 33,26 \\
Rasa & 4,31 & 10,31 & 4,16 & 42,84 \\
Kemasan & 4,25 & 10,16 & 3,06 & 31,11 \\
Labelitas & 3,94 & 9,41 & 3,84 & 36,17 \\
Harga sesuai kualitas & 4,16 & 9,93 & 3,09 & 30,73 \\
Produk mudah diperoleh & 4,16 & 9,93 & 3,09 & 30,73 \\
Stok & 3,63 & 8,66 & 3,63 & 31,40 \\
Lokasi strategis & 4,19 & 10,01 & 3,13 & 31,27 \\
Pengelolaan media & & & & \\
promosi & 2,78 & 6,65 & 3,25 & 21,60 \\
Iklan & 2,75 & 6,57 & 3,44 & 22,59 \\
\hline \multicolumn{1}{c}{ Total } & 41,84 & & 38,41 & 349,28 \\
\hline
\end{tabular}

Kuadran yang terakhir adalah Kuadran D, yaitu Possible overkill, Leave. Atribut yang berada di kuadran ini memiliki tingkat kepentingan rendah dengan tingkat kinerjanya yang tinggi. Hal ini menunjukkan bahwa pengalokasian sumber daya UMKM Apelnesia terlalu berlebihan di atribut tersebut dan perlu disebar untuk membantu atribut lainnya. Kedua atribut yang berada pada kuadran ini adalah desain produk (X1.2) dan stok produk (X3.2).

\section{Customer Satisfaction Index (CSI)}

Pengukuran tingkat kepuasan konsumen sangat penting dilakukan untuk mengetahui seberapa besar harapan yang dapat dipenuhi oleh produk sari apel UMKM Apelnesia. CSI memberikan data yang jelas mengenai tingkat kepuasan konsumen, sehingga pada satuan waktu tertentu dapat melakukan evaluasi secara berkala untuk memperbaiki apa yang kurang dan meningkatkan pelayanan (Widodo dan Sutopo 2018). Analisis ini dimulai dengan menghitung Mean Importance Score (MIS) dan Mean Satisfaction Score (MSS), lalu menentukan Weight Factor (WF), terakhir adalah menentukan Weighting Score (WS). Hasil analisis dapat dilihat di Tabel 8.

Berdasarkan hasil analisis, diperoleh nilai total dari Weighting Score (WS) adalah sebesar 349,28. Penentuan nilai Customer Satisfaction Index (CSI) yaitu dengan membagi nilai total WS dengan skala maksimum yang digunakan dalam penelitian ini yaitu 5 dan mengalikannya dengan 100 persen, maka dari itu nilai CSI yang diperoleh adalah 69,86 persen dengan keterangan bahwa konsumen produk sari apel UMKM Apelnesia merasa puas.

\section{Piramida Loyalitas}

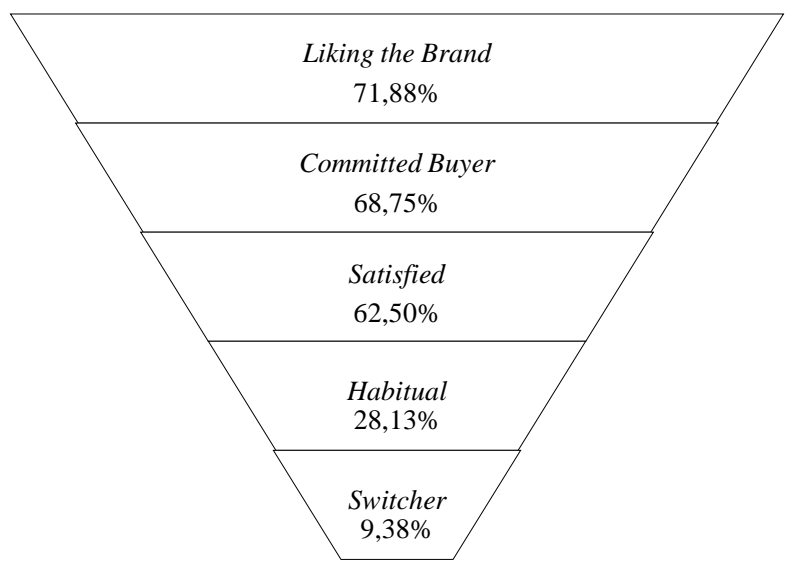

Gambar 2. Hasil Analisis Piramida Loyalitas

Tingkat loyalitas konsumen sari apel UMKM Apelnesia diukur dengan menggunakan Analisis Piramida Loyalitas yang terdiri dari tingkatan loyalitas seperti switcher buyer, habitual buyer, satisfied buyer, liking the brand, dan committed buyer. Responden disaring berdasarkan pemilihan skala likert 4 dan 5 pada item pertanyaan tingkat loyalitas konsumen lalu ditentukan persetansenya. Hasil persentase tersebut digambarkan dalam bentuk Piramida (Gambar 2), sehingga masingmasing tingkatan loyalitas dapat terlihat perbedaanya.

Pada Gambar 2, terlihat bahwa tingkatan loyalitas yang sebelumnya sudah di analisis menghasilkan bentuk piramida terbalik, hal ini menandakan bahwa brand equity dari produk sari apel UMKMApelnesia kuat, dikarenakan Committed buyer memiliki persentase jauh lebih tinggi yaitu 68,75 persen dibandingkan Switcher buyer yang hanya 9,38 persen. Hal ini sesuai dengan pendapat dari Durianto et al. (2004) yaitu brand equity yang kuat akan

membentuk suatu tingkatan brand loyalty yang berupa piramida terbalik, dimana Committed buyer akan lebih besar dari Switcher buyer. Manfaat dari brand equity adalah menumbuhkan loyalitas konsumen yang memungkinkan adanya pembelian ulang dan menganjurkannya ke orang lain.

\section{KESIMPULAN}

Berdasarkan hasil analisis yang telah dilakukan, dapat disimpulkan bahwa berdasarkan analisis model sikap Fishbein sikap konsumen produk sari apel UMKM Apelnesia yaitu cukup positif, dengan 
nilai atribut terbesar yaitu Rasa yang bernilai 17,92. Atribut yang dianggap penting berdasarkan analisis Importance Performance Analysis (IPA) adalah kualitas, rasa, dan labelitas. Atribut yang membutuhkan peningkatan secepatnya adalah kemasan, harga sesuai kualitas, produk mudah diperoleh, lokasi strategis. Atribut yang memiliki kinerja berlebih sehingga sumberdayanya perlu dialokasikan ke atribut lain adalah pengelolaan media promosi, iklan menarik, desain, dan stok. Kepuasan konsumen berdasarkan analisis Customer Satisfaction Index (CSI) yaitu puas. Konsumen produk sari apel UMKM Apelnesia dapat dikatakan loyal, dikarenakan nilai Committed buyer memiliki persentase jauh lebih tinggi yaitu 68,75 persen dibandingkan Switcher buyer yang hanya 9,38 persen.

\section{DAFTAR PUSTAKA}

Adrianto R. 2018. Sikap konsumen terhadap atribut beras organik. Jurnal PARSIMONIA, 4(3): 321-328. https://jurnal.machung.ac.id/ index.php/parsimonia/article/view/76.

$[12$ Januari 2020].

Anggraeni LD, Deoranto P, dan Ikasari D. 2015. Analisis persepsi konsumen menggunakan metode Importance Performance Analysis dan Customer Satisfaction Index. Industria: Jurnal Teknologi dan Manajemen Agroindustri, 4(2): 74-81.

https://industria.ub.ac.id/index.php/industri/art icle/view/179. [8 Maret 2020].

BPS [Badan Pusat Statistik]. 2019. Kota Batu dalam Angka 2019. https://batukota.bps.go.id/publication/2019/08 /16/cc143236cd063bd98ecdc875/kota-batudalam-angka-2019.html. [28 November 2019].

Balakrishnan, Bamini, Mohd I D dan Wong JYi. 2014. The impact of social media marketing medium toward purchase intention and brand loyalty among generation Y. Journal of Social and Behavioral Sciences, 148 (23): 177-185. https://www.researchgate.net/ publication/266205558_The_Impact_of_Socia 1_Media_Marketing_Medium_toward_Purcha se_Intention_and_Brand_Loyalty_among_Ge neration_Y. [1 November 2020].

Biesok G dan Wyród-Wróbel J. 2015. Approaches to Importance-Performance Analysis in Customer Satisfaction Surveys. Problemy Jakosci, $\quad$ 47(6): 26-31. https://www.researchgate.net/publication/322 519511_Decision_making_on_various_appro aches_to_Importance-
Performance_Analysis_IPA. [16 Januari 2020].

Devani V dan Rizko RA. 2016. Analisis kepuasan pelanggan menggunakan metode Customer Satisfaction Index dan Potential Gain In Customer Value. Jurnal Rekayasa dan Manajemen Sistem Informasi, 2(2): 17-28. http://ejournal.uinsuska.ac.id/index.php/RMSI /article/view/2605. [3 November 2020]

Durianto D, Sugiarto, dan Sitinjak T. 2004. Strategi Menaklukkan Pasar Melalui Riset Ekuitas dan Perilaku Merek. PT Gramedia Pustaka Utama. Jakarta.

Fitriana D, Florencia YKO, Dwi H, Utomo J, dan Tanto DS. 2014. Pengukuran kepuasan kontraktor terhadap kinerja klien pada proyek konstruksi swasta. Jurnal Karya Teknik Sipil, 3(1):

283-295. https://ejournal3.undip.ac.id/index.php/jkts/art icle/view/4690. [5 November 2020].

Hasan A. 2008. Manajemen Pemasaran dan Marketing. CV Alfabeta. Bandung.

Lusianti D. 2017. Pengukuran kepuasan peserta jkn melalui pendekatan Importance-Performance Analysis. Jurnal Sains Pemasaran Indonesia, 16(1): 17-25. https://ejournal.undip.ac.id/index.php/jspi/arti cle/view/14565. [7 Desember 2019].

Pratama DY, Indriani Y, dan Endaryanto T. 2017. Sikap dan kepuasan konsumen terhadap konsumsi makanan pecel lele di Kota Bandar Lampung. Jurnal Ilmu-Ilmu Agribisnis, 5(2): 200-205. https://jurnal.fp.unila.ac.id/index. php/JIA/article/view/1659. [23 November 2019].

Pratiwi AY, Deoranto P, dan Putri SA. 2014. Analisis atribut yang mempengaruhi keputusan pembelian dan pemetaan persepsi mie instan (Studi Kasus pada mahasiswa S1 Universitas Brawijaya). Jurnal Industria, 3(2): 107 - 118. https://industria.ub.ac.id/ index.php/industri/article/view/164. Februari 2020]

Saladin D. 2003. Intisari Pemasaran dan UnsurUnsur Pemasaran. Linda Karya. Bandung.

Santoso. 2011. Persepsi konsumen terhadap kualitas Bakpao Telo dengan metode Importance Performance Analysis (IPA). Jurnal Teknologi Pertanian, 12(1): 9-18. https://jtp.ub.ac.id/index.php/jtp/article/view/3 30. [18 November 2020]

Sukardi dan Cholidis C. 2006. Analisis tingkat kepuasan pelanggan terhadap produk corned pronas produksi PT CIP, Denpasar, Bali. Jurnal Teknologi Industri Pertanian, 18(2): 106-117. https://journal.ipb.ac.id/index.php/ 
Jurnal Ilmu Ilmu Agribisnis: Journal of Agribusiness Science, 9(3), Agustus 2021

jurnaltin/article/view/4756. [8 Desember 2019]

Suryani T. 2008. Perilaku Konsumen Implikasi pada Strategi Pemasaran. Graha Ilmu. Yogyakarta.

Widodo MS dan Sutopo J. 2018. Metode Customer Satisfaction Index (CSI) untuk mengetahui pola kepuasan pelanggan pada E-Commerce Model Business to Customer. Jurnal Informatika UPGRIS, 4(1): 38-45.
http://journal.upgris.ac.id/index.php/JIU/articl e/view/2224. [23 Desember 2019]

Widyasari R, Prasmatiwi FE, dan Situmorang S. 2014. Tingkat kepuasan dan loyalitas konsumen rumah tangga dalam mengonsumsi bihun jagung di Bandar Lampung. Jurnal Ilmu-Ilmu Agribisnis, 2(4): 382-389. https://jurnal.fp.unila.ac.id/index.

php/JIA/article/view/993. [5 Februari 2020]. 